\title{
Activation of the Medial Prefrontal Cortex Reverses Cognitive and Respiratory Symptoms in a Mouse Model of Rett Syndrome
}

\author{
C. James Howell, Michael P. Sceniak, Min Lang, Wenceslas Krakowiecki, Fatimah E. Abouelsoud, \\ (1) Saloni U. Lad, Heping Yu, and David M. Katz
}

DOI:http://dx.doi.org/10.1523/ENEURO.0277-17.2017

Department of Neurosciences, Case Western Reserve University School of Medicine, Cleveland, $\mathrm{OH} 44106$

\begin{abstract}
Rett syndrome (RTT) is a severe neurodevelopmental disorder caused by loss-of-function mutations in the gene encoding methyl-CpG-binding protein 2 (MeCP2; Amir et al., 1999), a transcriptional regulatory protein (Klose et al., 2005). Mouse models of RTT (Mecp2 mutants) exhibit excitatory hypoconnectivity in the medial prefrontal cortex (mPFC; Sceniak et al., 2015), a region critical for functions that are abnormal in RTT patients, ranging from learning and memory to regulation of visceral homeostasis (Riga et al., 2014). The present study was designed to test the hypothesis that increasing the activity of mPFC pyramidal neurons in heterozygous female Mecp2 mutants (Hets) would ameliorate RTT-like symptoms, including deficits in respiratory control and long-term retrieval of auditory conditioned fear. Selective activation of mPFC pyramidal neurons in adult animals was achieved by bilateral infection with an AAV8 vector expressing excitatory hm3D(Gq) DREADD (Designer Receptors Exclusively Activated by Designer Drugs) (Armbruster et al., 2007) under the control of the CamKIla promoter. DREADD activation in Mecp2 Hets completely restored long-term retrieval of auditory conditioned fear, eliminated respiratory apneas, and reduced respiratory frequency variability to wild-type $(\mathrm{Wt})$ levels. Reversal of respiratory symptoms following mPFC activation was associated with normalization of Fos protein levels, a marker of neuronal activity, in a subset of brainstem respiratory neurons. Thus, despite reduced levels of MeCP2 and severe neurological deficits, mPFC circuits in Het mice are sufficiently intact to generate normal behavioral output when pyramidal cell activity is increased. These findings highlight the contribution of mPFC hypofunction to the pathophysiology of RTT and raise the possibility that selective activation of cortical regions such as the mPFC could provide therapeutic benefit to RTT patients.
\end{abstract}

Key words: autism spectrum disorder; DREADD; hypofrontality; Mecp2; memory; mPFC

\section{Significance Statement}

Rett syndrome (RTT) is a devastating disorder for which no treatments are currently available beyond supportive care. Although significant progress has been made in understanding RTT pathophysiology at the molecular and cellular levels, the relationship between dysfunction in specific brain circuits and the expression of specific RTT symptoms remains unclear. The present study provides the first direct evidence of a link between hypoactivity in the MPFC and cognitive and respiratory symptoms in Mecp2 mutants by demonstrating that activation of the mPFC restores wild-type (Wt) function in these domains. Thus, in addition to highlighting the contribution of mPFC dysfunction to the pathophysiology of RTT, these findings raise the possibility that targeted activation of specific cortical regions could provide therapeutic benefit to $\mathrm{RTT}$ patients. 


\section{Introduction}

Rett syndrome (RTT) is caused by loss-of-function mutations in the gene encoding methyl-CpG-binding protein 2 (MeCP2) and is one of the most physically debilitating disorders on the autism spectrum. RTT patients exhibit a complex constellation of symptoms ranging from deficits in motor function and cognition to dysregulation of breathing and autonomic control (Amir et al., 1999). Studies in RTT mouse models, which recapitulate the symptomatology of human RTT, as well as human postmortem studies have revealed that loss of Mecp2 does not result in neuronal degeneration or cell loss (Akbarian, 2003) but rather in abnormalities in the structure and function of brain microcircuits (Shepherd and Katz, 2011). These changes include marked alterations in synaptic strength and connectivity (Katz et al., 2016) which differ among brain regions and appear to be reversible (Guy et al., 2007; Robinson et al., 2012). One of the most striking effects of Mecp2 loss on brain circuit function is a decrease in excitatory synaptic connectivity in the motor, somatosensory, visual, and midline limbic cortices, including the medial prefrontal cortex (mPFC; Katz et al., 2016). Cortical hypoconnectivity is associated with multiple factors, including reduced density and maturity of dendritic spines on pyramidal neurons (Chao et al., 2007; Belichenko et al., 2009; Kishi and Macklis, 2010; Stuss et al., 2012; Sceniak et al., 2015), a shift in the balance of excitatory and inhibitory synaptic signaling molecules toward decreased excitation (Durand et al., 2012; Sceniak et al., 2015) and, in some cases, increased inhibitory connectivity (Durand et al., 2012). As a result, many cortical regions in the Mecp2 mutant brain are hypoactive at rest compared to wild-type (Wt) controls (Kron et al., 2012).

Hypoactivity of pyramidal neurons in the mPFC in Mecp2 mutants is of particular interest given the role of the $\mathrm{mPFC}$ in multiple brain functions that are abnormal in $\mathrm{RTT}$, ranging from learning and memory to respiratory and autonomic homeostasis. Despite this, the role of mPFC

Received August 8, 2017; accepted December 1, 2017; First published December 21, 2017.

D.M.K. is a founding advisor to ArRETT Neuroscience, a company focused on advancing treatments for patients with Rett syndrome. All other authors declare no competing financial interests.

Author contributions: C.J.H., D.M.K., and M.P.S. designed research; C.J.H., M.P.S., S.U.L., and H.Y. performed research; C.J.H., M.P.S., M.L., W.K., and F.E.A. analyzed data; C.J.H. and D.M.K. wrote the paper.

This work was supported by National Institution of Neurological Disorders and Stroke Grants NS057398 (to D.M.K.) and NS098574-02 (to C.J.H.).

M. P. Sceniak's present address: University of Michigan 500 S State St., Ann Arbor, Ml 48109.

Acknowledgements: We thank lan Adams, Erica Kimmick, and Heping Yu for their expert technical assistance.

Correspondence should be addressed to David M. Katz, Department of Neurosciences, Case Western Reserve University School of Medicine, 10900 Euclid Avenue, Cleveland, OH 44106, E-mail: david.katz@case.edu.

DOI:http://dx.doi.org/10.1523/ENEURO.0277-17.2017

Copyright @ 2018 Howell et al.

This is an open-access article distributed under the terms of the Creative Commons Attribution 4.0 International license, which permits unrestricted use, distribution and reproduction in any medium provided that the original work is properly attributed. dysfunction in the pathophysiology of RTT has been little explored. For example, the ventral mPFC, or "visceral cortex" (Neafsey, 1990; Hassan et al., 2013), is responsible for regulating behavioral state-dependent changes in respiratory and autonomic homeostasis, as during stress or in response to conditioned learning (Frysztak and Neafsey, 1991; Alexandrov et al., 2007). Structures in the ventral mPFC, including the prelimbic (PL), infralimbic (IL), and dorsal peduncular cortex (dPC) give rise to extensive direct projections to cardiorespiratory cell groups in the pons and medulla, as well as indirect projections to subcortical forebrain cell groups that project to the brainstem, including the hypothalamus and amygdala (Gabbott et al., 2005). On the basis of these observations, we hypothesize that hypofunction of the mPFC may influence cardiorespiratory control in RTT. This possibility is supported by the fact that abnormal breathing in RTT worsens with stress and can be nearly normal during sleep, arguing strongly for a significant behavioral component (WeeseMayer et al., 2008; Ren et al., 2012). The ventral mPFC has also been shown to be required for cognitive tasks, such as fear memory consolidation and retrieval (Sierra-Mercado et al., 2006, 2011), that are disrupted in RTT. For example, Mecp2 mutants are impaired in their ability to retain memory of auditory conditioned fear $24 \mathrm{~h}$ after training (Tai et al., 2016), a task that requires ongoing activity in the PL (Corcoran and Quirk, 2007) and its projections to the dorsal midline thalamus (dMT; Adhikari et al., 2015). Therefore, the present study was designed to determine whether or not increasing activity in mPFC pyramidal neurons would ameliorate symptoms of cognitive impairment as well as abnormal breathing in Mecp2 mutant mice.

\section{Materials and Methods}

\section{Animals}

All experiments were performed on female Mecp2 $2^{\text {tm1. }}$ Jae Wt and Het mice on a 129S/BalbC/Bl6 background, and each animal was genotyped before and after every experiment to confirm genetic identity.

\section{Surgery and viral constructs}

Animals (8-10 weeks of age) were sedated with isoflurane (5\% for induction, $1.5-0.8 \%$ for maintenance), fixed in a stereotaxic frame (Stoelting) and then subjected to bilateral craniotomy at bregma $+1.75 \mathrm{~mm}, \pm 0.25 \mathrm{~mm}$ from the midline. Infusions of 500-nl viral construct (AAV8CamKIla-hm3D-mCherry; UNC vector core) were made at a depth of $2.0 \mathrm{~mm}$ using a Hamilton NeuroS syringe. For injections in the motor cortex, infusions were targeted at bregma $+1.9 \mathrm{~mm}, 1.5 \mathrm{~mm}$ from the midline, and $0.1 \mathrm{~mm}$ below the dorsal surface of the brain. To reduce backflow of the injectate along the needle path, infusions were performed at a rate of $100 \mathrm{nl}$ per 2 min with an additional 2 min following the final $100 \mathrm{nl}$. After surgery, animals were returned to their cages for two weeks to allow for viral expression. 

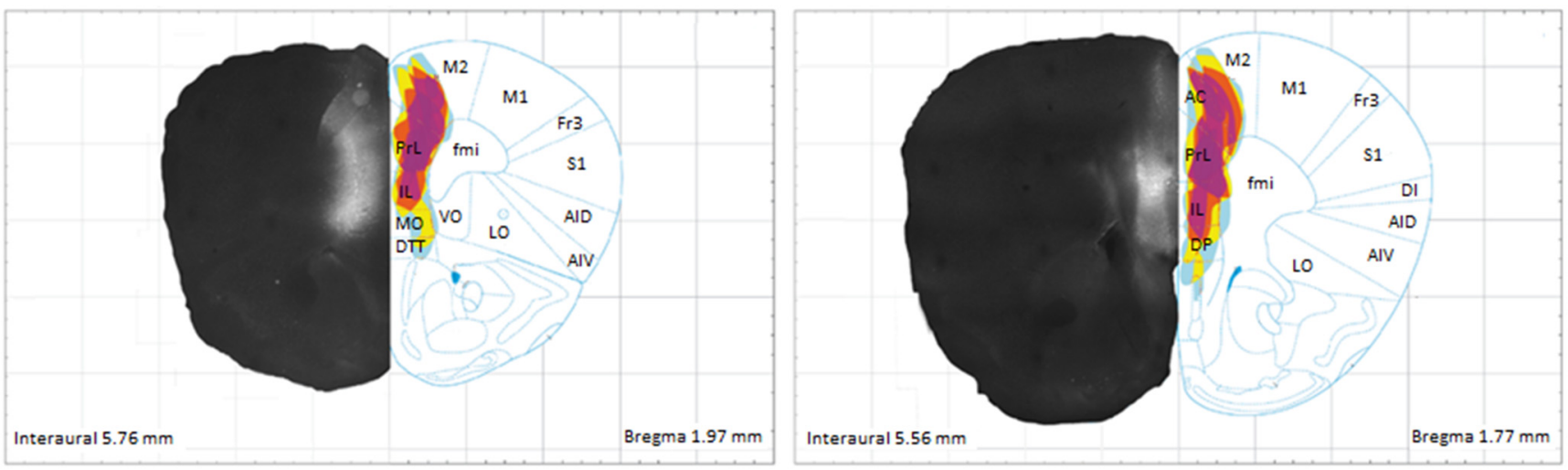

1
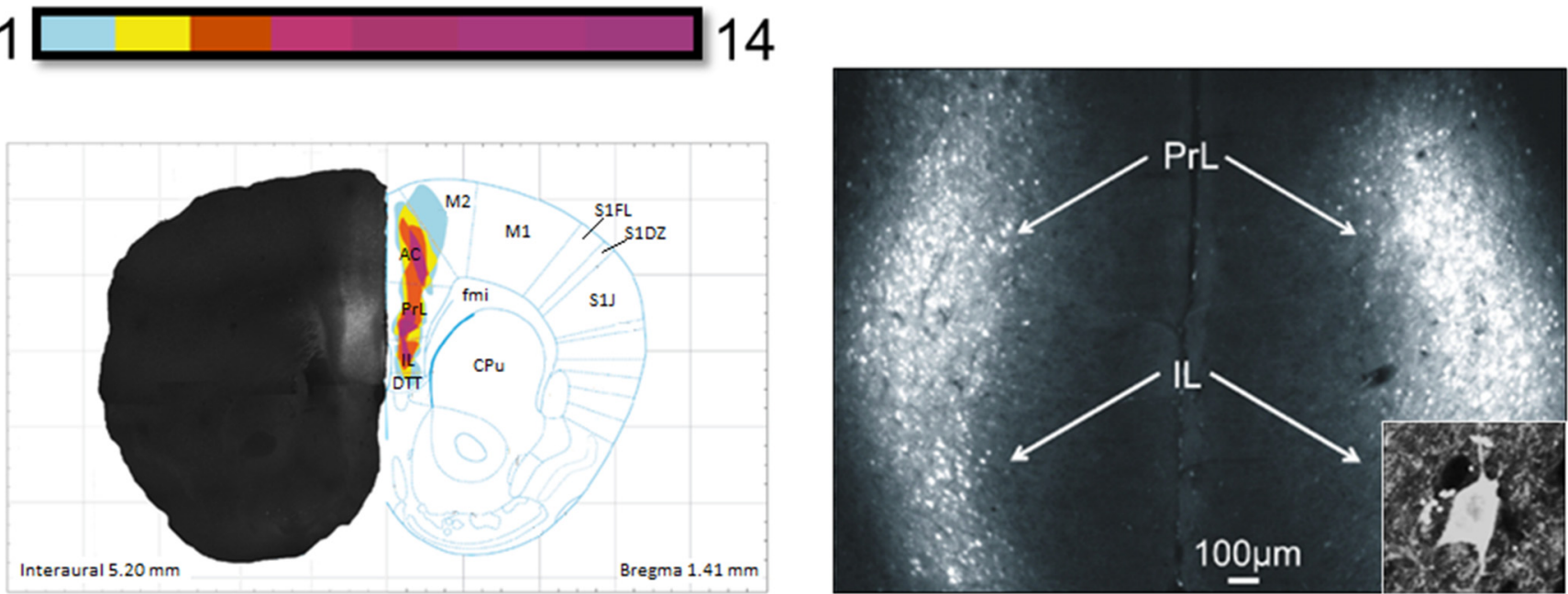

Figure 1. DREADD-Gq expression in the mPFC. The distribution of DREADD-Gq-labeled neurons was plotted from low-magnification micrographs of mCherry labeling in serial coronal sections through the forebrain in 14 animals; the plots were then overlaid to produce heat maps of the injection sites in which the color coding represents the extent of overlap in the distribution of labeled neurons in all 14 animals. These heat maps are shown on the right side of each figure, with representative hemi-brain sections shown on the opposite side (note that all animals received bilateral injections). The faint labeling seen lateral to the mPFC at 1.77 and $1.41 \mathrm{~mm}$ rostral to bregma is mCherry expression in the axons of infected neurons. Bottom right, Representative photomicrograph of mCherry-labeled neurons in a coronal section through the mPFC of an infected animal. Anatomic labels for this and all subsequent figures as follows: AC, anterior cingulate; AID, dorsal agranular insular cortex; AIV, ventral agranular insular cortex; CPu, caudate putamen; DI, dysgranular insular cortex; DP, dorsal peduncular cortex; DTT, dorsal tenia tecta; fmi, forceps minor of the corpus callosum; Fr3, frontal cortex area 3; IL, infralimbic cortex; LO, lateral orbital cortex; M1, primary motor cortex; M2, secondary motor cortex; MO, medial orbital cortex; PrL, prelimbic cortex; S1, primary somatosensory cortex; S1DZ, somatosensory cortex dysgranular zone; S1FL, forelimb region of the somatosensory cortex; S1J, jaw region of the somatosensory cortex; VO, ventral orbital cortex. Inset shows a high-magnification view of an infected neuron.

\section{Designer Receptors Exclusively Activated by Designer Drugs (DREADD)-Gq Expression Mapping}

To verify the distribution of DREADD-Gq labeling following injection (Fig. 1), low-magnification images of mCherry expression from a representative cohort of 14 injected animals (seven Wt and seven Het) were taken using a Zeiss Axiophot. These images were montaged using Adobe Photoshop, then overlaid onto coronal atlas images (Franklin and Paxinos, 2012). We then used Corel Draw tracing and lenses to create heat maps of DREADD-Gq expression showing the extent of overlap among all 14 animals. Additionally, these images were used to quantify the number of infected cells in the mPFC in Mecp2 Wt and Het mice. ImageJ was used to select and quantify the number of cells in a $200-\mu \mathrm{m}^{2}$ circular area surrounding each injection site. Data were collected from three tissue sections spanning the rostrocaudal extent of the injection sites from each of five animals per genotype.

\section{Electrophysiology}

In vivo extracellular recordings were made in a subset of mPFC-DREADD-Gq animals, two weeks after infection. Animals were anesthetized with urethane $(1000 \mathrm{mg} / \mathrm{kg})$ and placed in a stereotaxic apparatus (Stoelting). Craniotomies were made as described above and tungsten sharp electrodes (AM-Systems) were lowered into the MPFC at the same coordinates used for virus injections. Filtered extracellular recordings ( $1 \mathrm{kHz}$ high-pass) were amplified (AM-Systems) and digitally stored on a computer running custom software (Matlab) through an A/D converter 
(National Instruments). Extracellular recordings of spontaneous activity within the mPFC were collected under urethane anesthesia while simultaneously monitoring respiration. Recordings of spontaneous activity were collected during the baseline condition for $10 \mathrm{~min}$, and then $45 \mathrm{~min}$ after administration of clozapine- $\mathrm{N}$-oxide (CNO; $0.03 \mathrm{mg} / \mathrm{kg}$, i.p.) to determine the effects of mPFCDREADD-Gq activation on spiking activity. All animals were perfused after recordings to perform a histologic reconstruction of the recording site and to confirm the expression of the mCherry tag associated with the AAV8hm3-DREADD construct.

\section{Plethysmography}

Breathing analysis was performed on unrestrained mice using whole-body plethysmographs (EMMS) in which constant air flow was provided at $1 \mathrm{l} / \mathrm{min}$. Analysis was restricted to periods of quite breathing, defined as times when the animal was not involved in ambulation, grooming, or investigatory sniffing and all four paws were resting on the chamber floor. Animals were treated with either saline or CNO $(0.03 \mathrm{mg} / \mathrm{kg}$, i.p.) and then allowed to acclimate to the chamber for $1 \mathrm{~h}$. After acclimation, respiratory data were gathered over the next $2-3 \mathrm{~h}$. eDaq software (EMMS) was used to analyze the respiratory data for frequency, coefficient of frequency variation (CV), and apneas/min (where an apnea was defined as a respiratory pause lasting at least twice the duration of the average expiratory time, Te). Each animal served as its own control, being first injected with saline before plethysmography, then with CNO 24-48 $\mathrm{h}$ later, again followed by plethysmography. In addition, in one cohort of animals, respiration was measured a third time, 24-48 $\mathrm{h}$ after CNO injection and $1 \mathrm{~h}$ following saline treatment.

\section{Cue-dependent fear conditioning}

Animals were habituated in a fear conditioning chamber (Med Associates) for $90 \mathrm{~s}$ before being exposed to four sequential pairings of a $5 \mathrm{kHz}, 80 \mathrm{~dB}$ tone for $30 \mathrm{~s}$ (conditioned stimulus; CS) which coterminated with a 0.5-mA foot shock (unconditioned stimulus; US); each pairing was separated by 30 -s interstimulus intervals and the time spent immobile during the CS presentation is reported as \% freezing. Animals that did not learn the CS-US pairing, i.e., that did not exhibit increased freezing during conditioning, were excluded from further analysis. To assess short-term memory (STM) retrieval ( $4 \mathrm{~h}$ after CS-US pairing), animals were exposed to the CS alone, repeated twice with a $30-s$ interval, and the \% freezing during the two CS exposures was averaged. These data are displayed as a percentage of the freezing to CS4 during conditioning ([Freezing Tone(LTM or STM) $* 100] /$ Freezing $_{\text {CS4 } 4}$ ). Long-term memory retrieval was tested $24 \mathrm{~h}$ after fear conditioning using the same protocol as described for STM retrieval testing. To avoid environmental context as a confounding variable, both STM and long-term memory (LTM) testing were performed in a novel environment produced by modifying the fear conditioning chamber with a white floor, black a-frame insert, black and white striped background, and a vanilla scent. Some of the animals used for fear conditioning were heterozygous carriers of Thy1-EGFP MJrs/J that were generated by crossing homozygous male Thy1-EGFP ${ }^{M J r s / J}$ mice on a $\mathrm{Bl} 6$ background with heterozygous female Mecp2 $2^{\text {tm1.1 Jae }}$ mice from our main colony. The presence of the transgene was incidental to the present study; these animals were included to increase group sizes during a period of limited animal availability and did not differ in performance from the main colony stock on either fear memory acquisition or short- and long-term fear memory retrieval $(p=0.49$, $p=0.51, p=0.92$, respectively by Student's $t$ test, comparing animals with and without the transgene).

\section{Immunohistochemistry}

After behavioral testing, mice were deeply anesthetized with isoflurane and then perfused with $0.9 \%$ saline, followed by $4 \%$ paraformaldehyde (PFA) by cardiac perfusion. PFA fixed brains were sectioned at $40 \mu \mathrm{m}$ on a cryostat microtome (Jung Frigocut 2800N). Free floating sections were exposed to a primary antibody directed against either mCherry (Life technologies M11217; 1:500) or Fos protein (SySy 226003; 1:3000) overnight at room temperature. The next day, the tissue was incubated sequentially with a biotinylated secondary antibody (Jackson \#112-065-003; 1:400 or Vector BA1000), ABC kit (Vector), and developed with the Sigmafast diaminobenzidine kit. Mounted sections were imaged using a light microscope (Zeiss Axiophot) and photographed with a CCD camera (Q-Imaging).

\section{Blinding and randomization}

Animals were selected for all experiments, and assigned to experimental groups without prior knowledge of phenotypic severity. For fear conditioning experiments and Fos-labeling studies, the investigators were blind to genotype and treatment group at all stages including data analysis. Blinding for treatment group was not necessary for plethysmography and electrophysiology experiments because each animal received both saline and $\mathrm{CNO}$ and thereby served as its own control.

\section{Statistics}

Minimum group sizes were determined using G*Power 3 power analysis software (Faul et al., 2007). Each data set was tested for normality using the Shapiro-Wilk test in the Statistical Package for Social Sciences (SPSS), and parametric tests were performed either on the raw data for normally distributed data sets or on log transformed data for non-normally distributed data sets.

\section{Results}

\section{DREADD expression in mPFC pyramidal neurons}

To enable selective activation of mPFC pyramidal neurons, we injected an AAV8 viral construct expressing the excitatory DREADD AAV8-CamKIla-hm3DmCherry (DREADD-Gq; UNC Vector Core) bilaterally into the mPFC of female Wt and Mecp2 ${ }^{\text {tm1.1.1Jae/+ }}$ (Het) littermates (bregma $+1.75 \mathrm{~mm}, \pm 0.25 \mathrm{~mm}$ from the midline, -2.00 $\mathrm{mm}$ depth). Following injection of the viral construct, two weeks were allowed for the expression of DREADD-Gq in the infected neurons before beginning subsequent experimental protocols. Reconstruction of the injection sites 


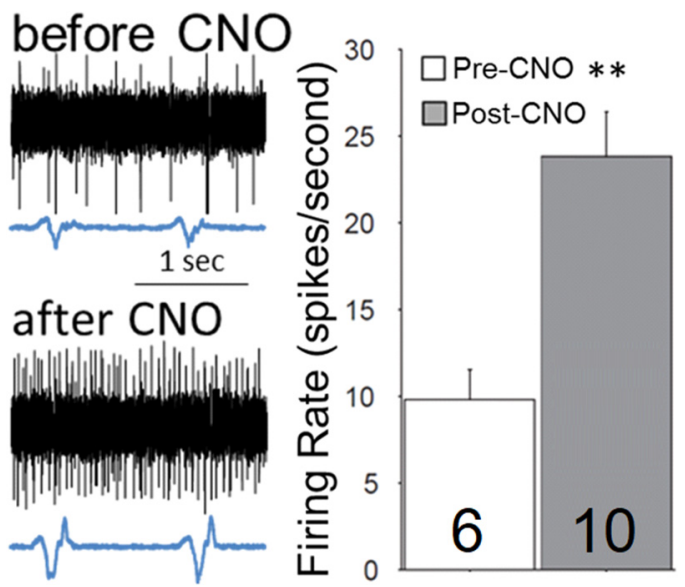

Figure 2. Activation of mPFC pyramidal neurons by DREADD-Gq increases neuronal activity in vivo. Left, Representative extracellular traces of spontaneous activity in the mPFC of mPFCDREADD-Gq Het animals before and after CNO treatment. Right, Summary data from two animals; the total number of recorded cells is shown within each bar. $* * p<0.01$ by Wilcoxon rank sum test.

from 14 animals revealed that our injection coordinates generated bilateral infection of neurons in the pre- and infra-limbic cortices (PL and IL, respectively) with some spread into the dPC cortex ventrally, and the cingulate (CG) and motor cortices (MCtxs) dorsally (Fig. 1; see Methods for details). Animals that displayed either unilateral expression or expression surrounding the lateral ventricles were eliminated from further analysis. To compare the efficiency of viral transduction in Wt and Het animals, we estimated the number of DREADD-mCherry positive cells in the injection site in a subset of animals (see Materials and Methods for details) and found no difference between genotypes (Wt, $106.13 \pm 8.59$ vs null, $106.233 \pm 11.13$ ). Consistent with previous evidence that AAV8 is not transported either transynaptically or in the retrograde direction (Aschauer et al., 2013), we found no cell bodies labeled with DREADD-Gq outside of the regions mentioned above.

To verify that CNO injection altered neuronal activity in the mPFC of mPFC-DREADD-Gq-infected Het mice, we analyzed in vivo extracellular recordings of spiking activity before and after CNO administration $(0.03 \mathrm{mg} / \mathrm{kg}$, i.p.) in anesthetized animals. These experiments revealed that the firing rate of neurons in the MPFC increased $>2$-fold after CNO (average firing rate $19.67 \pm 3.43$ pre-CNO vs $47.60 \pm 5.20$ post-CNO; Wilcoxon rank sum test; Fig. 2), consistent with previous studies (Armbruster et al., 2007; Alexander et al., 2009; Ferguson et al., 2011; Krashes et al., 2011; Atasoy et al., 2012; Kong et al., 2012; Stachniak et al., 2014; Chen et al., 2015; Scofield et al., 2015; Urban and Roth 2015; Vardy et al., 2015).

\section{DREADD-positive fibers project to brain regions important for respiratory control and cue-dependent fear memory}

To begin elucidating how activation of the MPFC might impact Mecp2 mutant respiratory and cognitive pheno- types, we asked whether or not mPFC-DREADD-Gqinfected neurons project to regions known to be important for either respiratory control or cue-dependent fear memory. To approach this issue, we took advantage of the fact that the mCherry tag in the DREADD-Gq construct can be visualized throughout the infected neurons, including their axonal projections, and amplified by immunocytochemical staining. Analysis of brain sections from mPFC-DREADDGq-infected animals revealed extensive projections of mCherry-labeled axons within numerous components of the ponto-medullary respiratory network, including the parabrachial nucleus and locus coeruleus in the pons, and the caudal raphe, nucleus of the solitary tract (nTS) and ventrolateral reticular formation in the medulla (Fig. 3). Corticobulbar projections to the medulla could be clearly seen exiting the pyramidal tract before ramifying dorsally in the caudal raphe and nTS and laterally in the ventrolateral medulla (VLM; Fig. 3). Fibers were also present in mid- and forebrain structures that influence breathing and project to the ponto-medullary network, including the periaqueductal gray (PAG), hypothalamus, and the basolateral nucleus of the amygdala (BLA), a structure which is also critically important for cue-dependent fear memory consolidation.

\section{Increasing mPFC pyramidal neuron activity restores normal respiration in Mecp2 mutants}

To determine whether or not changes in the activity of mPFC pyramidal neurons would alter Mecp2 mutant respiratory phenotypes, we compared breathing in mPFCDREADD-Gq-infected $\mathrm{Wt}$ and Het animals $1 \mathrm{~h}$ after injection of either saline (control) or the DREADD ligand CNO, using whole-body plethysmography (Fig. 4, experimental timeline). In a subset of animals, saline was also given 24-48 h after CNO, and animals were again tested by plethysmography to determine the reversibility of any observed effects of the DREADD ligand. To address the possibility that CNO may have nonspecific effects on respiration (Loffler et al., 2012; Gomez et al., 2017), we also analyzed the respiratory response to $\mathrm{CNO}$ in Hets that had not been infected with DREADD-Gq (naïve Hets).

As previously described for Mecp2 mutants (Katz et al., 2016), naïve Hets treated with CNO, as well as mPFCDREADD-Gq-infected Hets treated with saline exhibited significantly more apneas than Wt animals (ANOVA with Bonferroni post hoc test; Fig. 4). However, in mPFCDREADD-Gq-infected Hets treated with CNO, the apnea score was reduced to Wt levels (apneas/min; Wt Gq saline, $0.33 \pm 0.16$; Het $\mathrm{Gq}$ saline, $0.87 \pm 0.15$; Het $\mathrm{Gq}$ CNO, $0.29 \pm 0.06$; Fig. 4). This effect was completely reversible as mPFC-DREADD-Gq-infected Het mice injected with saline 24-48 $\mathrm{h}$ after receiving $\mathrm{CNO}$ exhibited the same level of apnea as they did before CNO (Het Gq saline \#2, $0.91 \pm 0.20$; Fig. 4). To determine whether or not CNO activation of neurons infected by spread of the virus into the MCtx contributed to the apnea rescue in mPFC-DREADD-Gq-infected Hets, a parallel series of experiments was performed in animals in which DREADD-Gq infection was restricted to the MCtx. CNO injection had no effect on the number of apneas in these animals (Stu- 


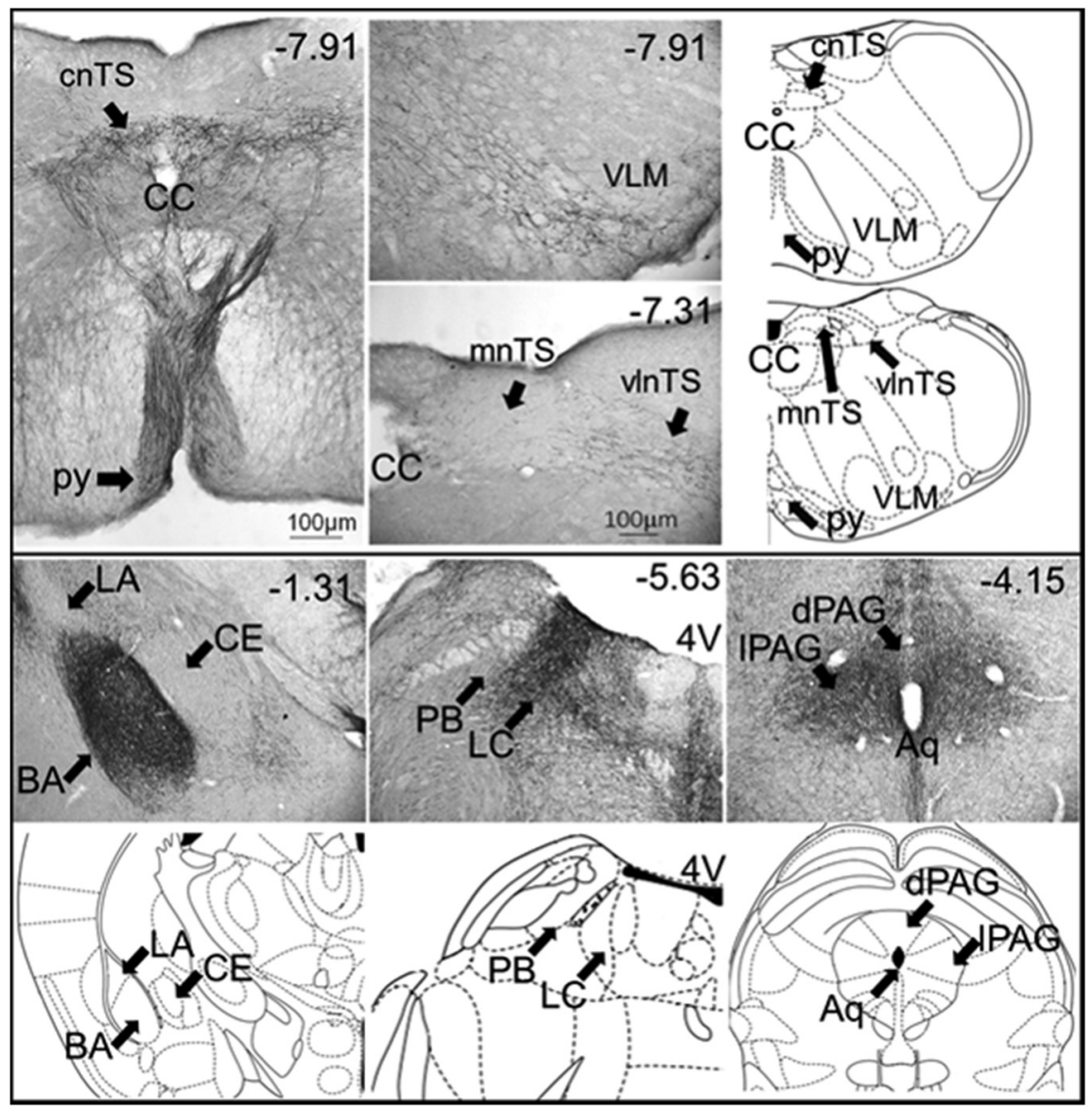

Figure 3. Photomicrographs showing mCherry-positive fibers in coronal sections through brain regions important for respiratory control and cue-dependent fear memory following DREADD-Gq infection of the mPFC. Numbers in the top right of each micrograph correspond to the distance from bregma $(\mathrm{mm})$. 4V, fourth ventricle; Aq, aqueduct of Sylvius; BA, basal amygdala; CC, central canal; CE, central amygdala; cnTS, commissural nTS; LC, locus coeruleus; LA, lateral amygdala; mnTS, medial nTS; PB, parabrachial nucleus; py, pyramidal tract; vInTS, ventrolateral nTS (abbreviations from Franklin and Paxinos, 2012).

dent's $t$ test; Het MCtx saline, $1.04 \pm 0.34$; Het MCtx CNO, $1.24 \pm 0.52$; Fig. 5). Together, these data demonstrate that activation of excitatory neurons in the mPFC can eliminate the apnea phenotype in Mecp2 Hets.

We next sought to determine whether CNO treatment of animals expressing DREADD-Gq in the mPFC impacted other respiratory phenotypes previously observed in Mecp2 mutant mice (Katz et al., 2016). Therefore, we analyzed both instantaneous respiratory frequency and the $\mathrm{CV}$. Although we found no effect of either genotype or treatment on respiratory frequency (Fig. 6), CV was significantly increased in DREADD-Gq Hets treated with saline compared to DREADD-Gq Wt controls (Wt Gq saline, $100.00 \pm 4.77$, Het Gq saline, $117.41 \pm 6.71 \mathrm{CV}$; Fig. 6). In contrast, $\mathrm{CNO}$ treatment of Hets expressing DREADD-Gq in the mPFC restored CV to Wt levels (Het Gq CNO, $96.85 \pm$ $7.60 \mathrm{CV}$; ANOVA with LSD post hoc test; Fig. 6). The increase in CV in Het mice, and the subsequent CV rescue following CNO treatment could be attributed to the effects of genotype and treatment, respectively, on the number apneic pauses, as these effects disappeared when CV was calculated with apneas removed (data not shown).

\section{DREADD activation of mPFC pyramidal neurons impacts downstream function in respiratory-related neurons}

To determine whether activation of the mPFC in Mecp2 mutants altered neuronal activity in downstream respiratory targets, we used immunocytochemical staining to compare expression of Fos protein in response to CNO treatment in mPFC-DREADD-Gq-infected Wt and Het animals. We previously showed that Fos, the protein product of the activity-dependent immediate early gene, cFos, is a sensitive and accurate marker of differences in neural circuit activity between Wt and Mecp2 mutant mice (Kron et al., 2012). We focused in particular on the respiratory subnuclei of the nTS, which exhibit synaptic hyperexcitability and markedly increased Fos expression in Mecp2 mutants compared to Wt (Kron et al., 2012). Synaptic hyperexcitability in respiratory subnuclei of nTS, including those involved in regulation of the inspiratory off-switch through the Hering-Breuer reflex pathway, is thought to be a substrate for respiratory hyperreflexia in Mecp2 mutants and may thereby contribute to apneic breathing (Kron et al., 2012; Dhingra et al., 2013). In the present study, CNO treatment of mPFC-DREADD-Gq-infected 


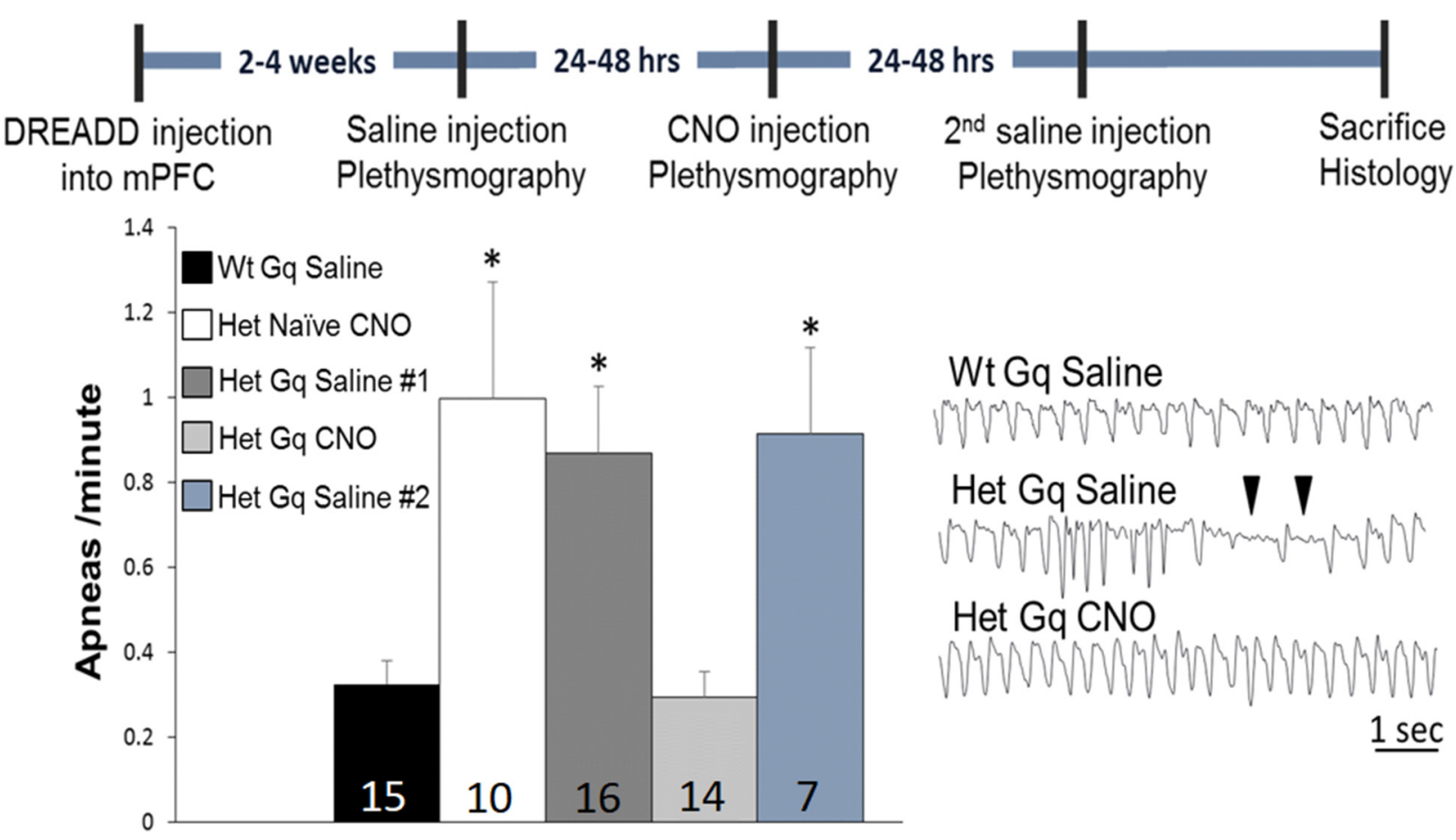

Figure 4. DREADD-Gq activation of pyramidal neurons in the mPFC eliminates the apneic breathing phenotype in Mecp2 mutants. The timeline of DREADD injection, CNO (or saline) treatment and plethysmographic recordings is shown at the top of the figure. The bar graph shows summary data illustrating the apneas/min for each experimental group with group sizes included within each bar. $* p<0.05$ by ANOVA with Bonferroni post hoc test. Bottom right, Representative respiratory traces; $\boldsymbol{\nabla}$ indicates typical respiratory pauses scored as apneas.

Het mice reduced Fos expression in nTS subnuclei to Wt levels (average Fos + expression Wt Gq saline, $19.56 \pm$ 5.76, Het Gq saline, $45.15 \pm 15.06$, Het Gq CNO, $14.59 \pm$ 2.68; ANOVA with LSD post hoc test; Fig. 7), indicating that activation of mPFC pyramidal neurons can impact neuronal function in downstream respiratory targets. Similar changes were not seen in other brainstem respiratory cell groups, including the VLM and PAG [dorsal PAG (dPAG); Wt Gq saline, $48.23 \pm 8.11$, Het Gq saline, $50.38 \pm$ 9.83; Het Gq CNO, $79.32 \pm$ 12.58; lateral PAG (IPAG); Wt Gq saline, $152.58 \pm 14.19$, Het Gq saline, 169.51 \pm 27.71 ; Het Gq CNO, $209.24 \pm$ 16.34; VLM; Wt Gq saline, $70.19 \pm$ 12.32, Het Gq saline, $86.99 \pm 13.60$; Het Gq CNO, $72.43 \pm$ 14.67; Fig. 7], although there was a trend toward increased expression in the dPAG in the Het Gq CNO group.

\section{DREADD activation of mPFC pyramidal neurons restores long-term retrieval of auditory conditioned fear}

In addition to cortical modulation of visceral homeostasis, the mPFC plays critical roles in cognition that are mediated through projections to diverse cortical and subcortical cell groups (Vertes, 2004; Gabbott et al., 2005). In particular, direct projections from mPFC pyramidal neurons to the BLA mediate the consolidation of auditory conditioned fear memory following conditioned fear learning, and the short-term retrieval of this memory while mPFC projections to the dMT mediate long-term retrieval (Do-Monte et al., 2015). The following series of experi- ments was designed to determine whether or not hypoactivity in the mPFC was associated with a deficit in retrieval of auditory conditioned fear memory and, if so, whether the deficit is reversible by DREADD activation of mPFC pyramidal neurons. To approach these issues, we compared acquisition and retrieval of auditory conditioned fear memory among five groups of animals; noninfected Het control animals given either saline or CNO (0.03 mg/kg, i.p.), mPFC-DREADD-Gq-infected Het animals treated with either CNO or saline, and mPFCDREADD-Gq-infected Wt animals treated with saline; all groups received saline or $\mathrm{CNO}, 1 \mathrm{~h}$ before training. Animals were trained with exposure to pairings of CS and US across four trials (CS $=5 \mathrm{kHz}, 80 \mathrm{~dB}$ tone; US $=0.5-\mathrm{mA}$ shock coterminating with the last second of the CS). No significant differences in learning were observed between groups across the four conditioning trials (CS4-CS1\% freezing; Wt Gq saline, $44.25 \pm 4.66$; Het Gq saline, $38.51 \pm$ 5.40; Het naïve saline, $38.56 \pm 6.18$; Het naïve $C N O$, $34.05 \pm 4.37$; Het Gq CNO, $33.25 \pm 3.80$; ANOVA with LSD post hoc test; Fig. 8). To measure fear memory retrieval, animals were subsequently exposed to the CS alone at $4 \mathrm{~h}$ after training (testing STM) and $24 \mathrm{~h}$ after training (testing LTM; Schafe and LeDoux, 2000). No significant differences were observed among the groups $4 \mathrm{~h}$ after training [freezing (\%CS4); Wt Gq saline, $102.62 \pm$ 8.00; Het Gq saline, $78.73 \pm 5.06$; Het naïve saline, $93.06 \pm$ 15.80; Het naïve CNO, $82.96 \pm 8.02$; Het Gq CNO, 78.14 \pm 8.27; ANOVA with LSD post hoc test; Fig. 8]. However, $24 \mathrm{~h}$ after training, mPFC-DREADD-Gq-infected Het mice 

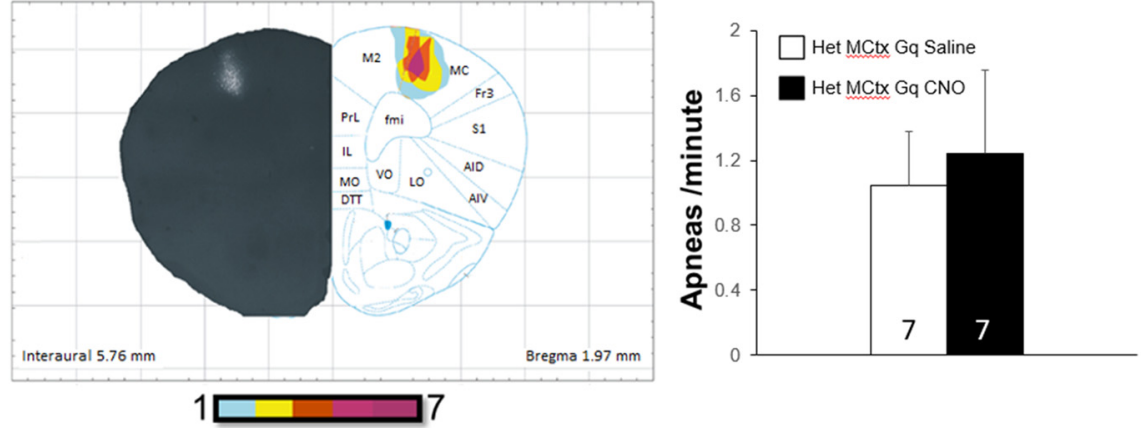

Figure 5. Activation of pyramidal neurons in the motor cortex by DREADD-Gq does not alter respiration. Left, The distribution of DREADD-Gq-labeled neurons was plotted from low-magnification micrographs of mCherry labeling in coronal sections through the forebrain in all animals tested; the plots were then overlaid to produce a heat map of the injection sites in which the color coding represents the extent of overlap in the distribution of labeled neurons in all seven animals. Note that all animals received bilateral injections. Right, Animals expressing DREADD-Gq in the motor cortex were subjected to two consecutive days of plethysmographic recording of respiration, $1 \mathrm{~h}$ following either saline treatment (day 1) or CNO treatment (day 2). The bar graph shows summary data illustrating the apneas/min on day 1 (saline) and day 2 (CNO), with group sizes included within each bar.

treated with saline exhibited a significant deficit in their freezing response, as did noninfected Het controls treated with either saline or CNO, compared to mPFC-DREADDGq-infected Wt mice. In contrast, the freezing response in mPFC-DREADD-Gq-infected Het mice treated with CNO was indistinguishable from mPFC-DREADD-Gq-infected Wt mice treated with saline [freezing (\%CS4); Wt Gq saline, $125.53 \pm 11.42$; Het Gq saline, $70.67 \pm 8.42$; Het naïve saline, $81.98 \pm 12.23$; Het naïve CNO, $87.05 \pm 6.19$; Het Gq CNO, $123.16 \pm 16.87$; ANOVA with LSD post hoc test; Fig. 8]. These data demonstrate that activation of the mPFC in Mecp2 mutants can restore long-term retrieval of auditory conditioned fear memory to Wt levels, $24 \mathrm{~h}$ after training. Given that the duration of CNO action is $\sim 6 \mathrm{~h}$ (Whissell et al., 2016), these data indicate that transient activation of the mPFC in Mecp2 mutants leads to a durable change in mechanisms underlying fear memory retrieval.

\section{Discussion}

The present findings demonstrate the importance of mPFC hypofunction in RTT by showing that activation of mPFC pyramidal neurons can reverse abnormalities in breathing and long-term retrieval of conditioned fear learning in Mecp2 Het mice, a model of RTT that recapitulates the genetic mosaicism and many phenotypic characteristics of the human disorder. It seems likely that distinct mechanisms downstream of enhanced pyramidal neuron activity underlie the reversal of these respiratory and cognitive abnormalities, respectively. This is underscored by the fact that the normalization of respiratory apneas and respiratory variability was transient and undetectable $24 \mathrm{~h}$ after CNO treatment, the same time point at which fear memory retrieval was rescued in mPFCDREADD mutants. These differences could be explained by the fact that different populations of MPFC neurons innervate brainstem versus cortical and subcortical fore-
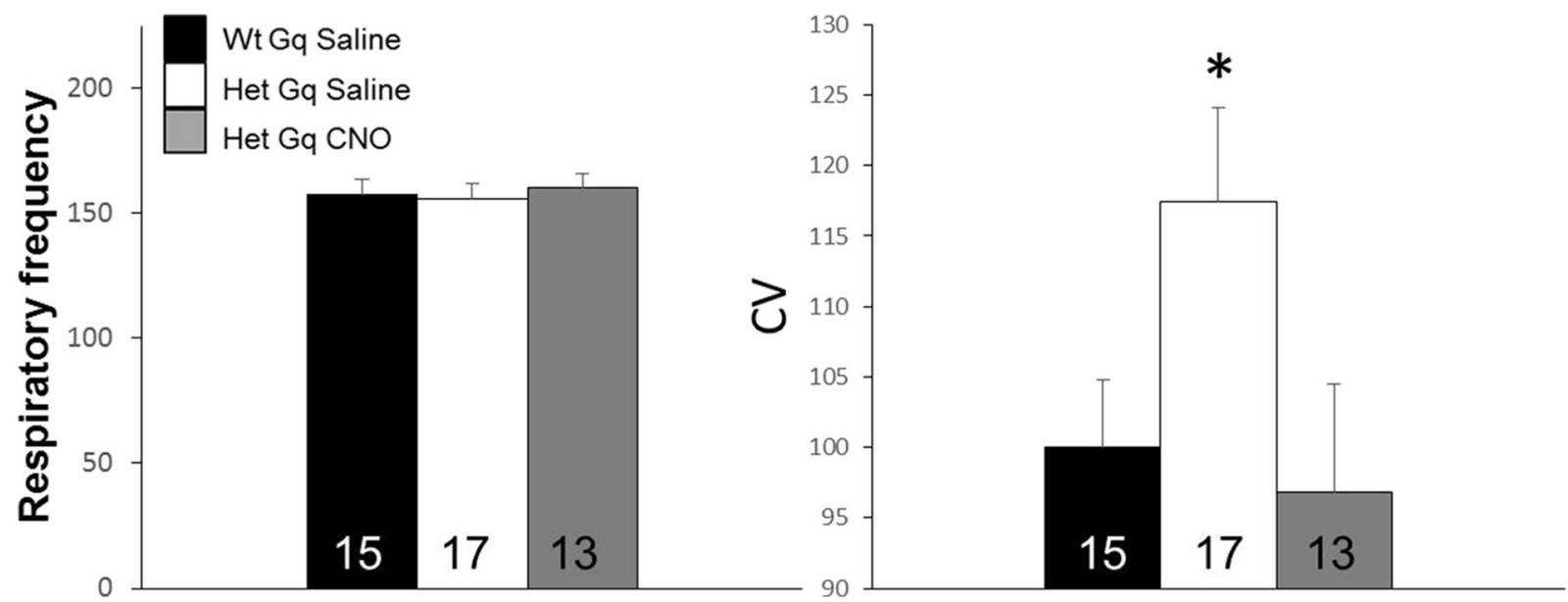

Figure 6. DREADD-Gq activation of pyramidal neurons in the mPFC reduces respiratory frequency variability to Wt levels without impacting the average frequency of respiration. Left, Summary data showing the mean instantaneous respiratory frequency for each experimental group. Right, Summary data showing the coefficient of variation (CV) for instantaneous respiratory frequency for each experimental group. Group sizes are shown within each bar. $* p<0.05$ by ANOVA with LSD post hoc test. 

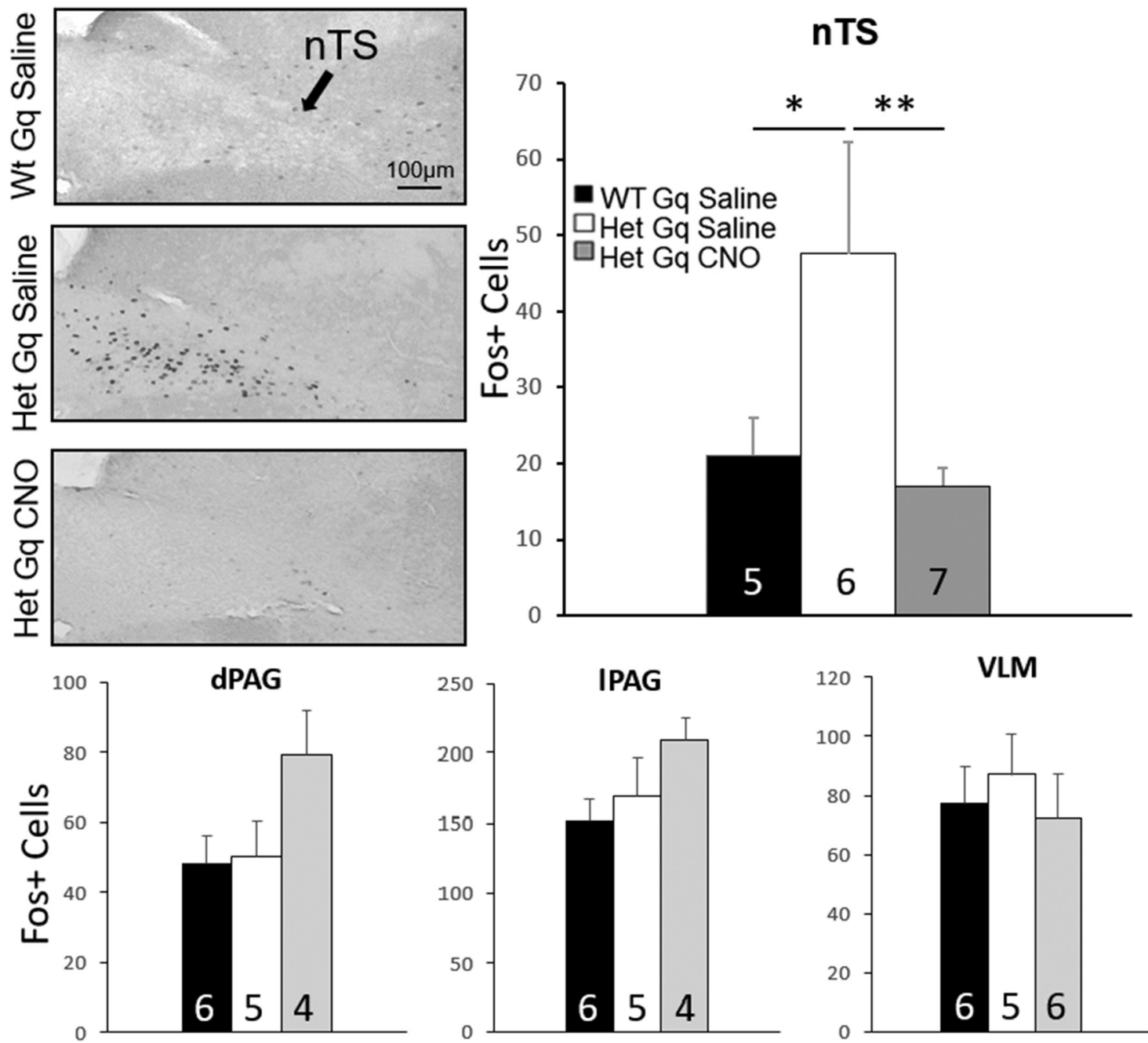

Figure 7. Activation of mPFC pyramidal neurons by DREADD-Gq impacts neuronal function in respiratory subnuclei of the nTS. Animals were sacrificed 90 min after either saline CNO injection and processed for Fos immunostaining. Photomicrographs show representative sections through the caudal nTS from 3 different animals, each of which received bilateral injections of DREADD-Gq in the mPFC. CNO treatment restored Fos levels in the nTS of mPFC-DREADD-Gq Het mice to Wt levels. $* p<0.05, * * p<0.01$, ANOVA with LSD post hoc test. No significant differences were observed between treatment groups in the dPAG, IPAG or VLM.

brain targets (Gabbott et al., 2005). In general, loss of Mecp2 is thought to disrupt resting breathing by shifting synaptic excitatory-inhibitory balance toward increased excitability at multiple loci throughout the brainstem respiratory network (Stettner et al., 2007; Katz et al., 2009; Ramirez et al., 2013). We hypothesize, therefore, that activation of the MPFC normalizes resting breathing in Het mice by acutely modulating hyperexcitability of the brainstem network. Moreover, our data suggest that loss of cortical modulation resulting from hypoactivity of pyramidal neurons in the mPFC may underlie or contribute to behavioral dysregulation of breathing in RTT (Sceniak et al., 2015). Based on the projections of mPFC-DREADDGq-infected neurons, the modulation of respiratory output that we observed could have been mediated by direct corticobulbar inputs to ponto-medullary respiratory cell groups, including the nTS, VLM, and LC, and/or by projections to structures that indirectly modulate breathing, such as the hypothalamus, amygdala, and PAG. The fact that mPFC activation can normalize mutant levels of Fos expression in respiratory subnuclei of nTS suggests that cortical inputs may influence the breathing pattern in RTT, at least in part by modulating hyperexcitability of brainstem neurons involved in reflex regulation of respiratory motor output. Such a mechanism would be consistent with previous studies demonstrating that the MPFC regulates gain and sensitivity of cardiovascular reflexes mediated by the nTS (Hassan et al., 2013; Fassini et al., 2016; Scopinho et al., 2009). However, given the complexity of the brainstem respiratory network, we cannot rule out the possibility that stabilization of the breathing pattern in DREADD-activated mutants involves alterations in excitatory/inhibitory balance in structures other than the nTS as well (Abdala et al., 2016).

Further studies will be required to determine which subregion(s) of the MPFC are responsible for the rescue of Het breathing phenotypes described here, as the PL, IL, and $\mathrm{dPC}$ all have direct and/or indirect connections with 

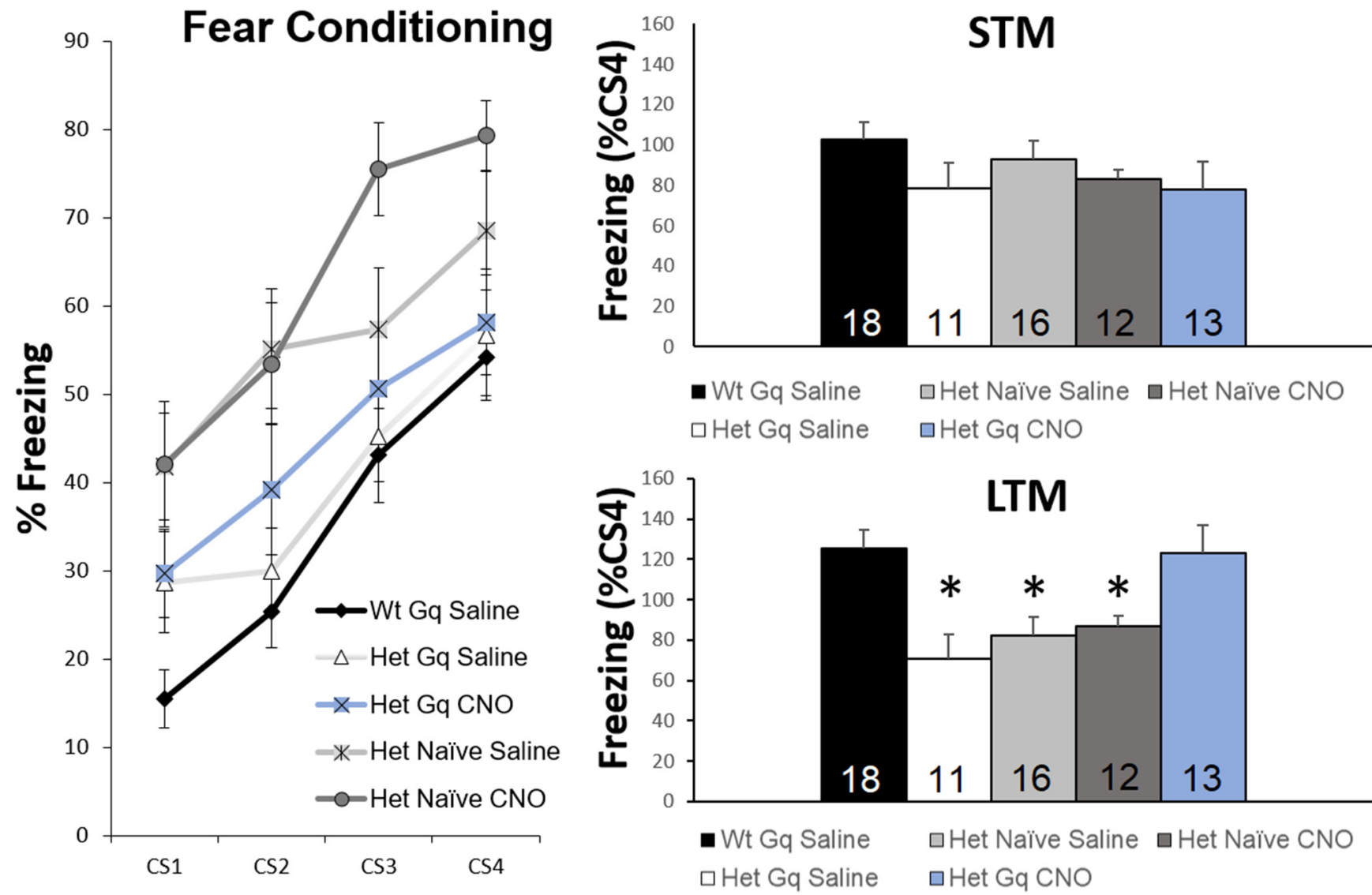

Figure 8. Activation of mPFC pyramidal neurons by DREADD-Gq rescues long-term expression of cue-dependent fear memory. Left, Conditioning to CS-US pairings across four trials demonstrates similar responses in all groups using \% freezing (immobility) during the CS presentations as an index of fear learning. Right, Short-term ( $4 \mathrm{~h}$ after conditioning) and long-term ( $24 \mathrm{~h}$ after conditioning) memory retrieval were tested by exposure to the CS alone, with the animal in a test chamber that was distinguished from the conditioning chamber by novel environmental features (see Materials and Methods). Data are presented as a percentage of the

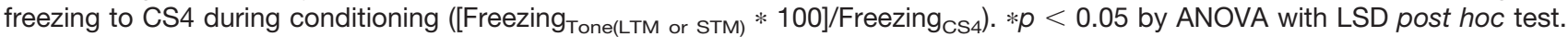

brainstem nuclei involved in cardiorespiratory control (Gabbott et al., 2005), as well as the impact of DREADD activation of MPFC pyramidal neurons on the strength of these connections. More generally, there is growing appreciation for the fact that hypofrontality (Pratt et al., 2008), and abnormalities in the corticofugal projection network in particular contribute to the pathophysiology of diverse neuropsychiatric diseases (Shepherd, 2013). However, despite the long-standing recognition that respiratory dysfunction in RTT exhibits features of limbic cortical dysfunction (Woodyatt and Murdoch, 1996), a role for prefrontal corticofugal influences on breathing abnormalities in RTT has not previously been described. By highlighting the ability of corticofugal pathways to modulate respiratory output in Mecp2 mutants, these findings raise the possibility that cortical influences on breathing could be harnessed to improve respiratory control in RTT.

Ongoing activity of mPFC pyramidal neurons is also critical for diverse cognitive tasks, including consolidation and retrieval of cue-dependent fear conditioning, which requires activity of neurons projecting from the MPFC to the BLA and the dMT for short- and long-term retrieval, respectively (Corcoran and Quirk, 2007; Adhikari et al., 2015; Do-Monte et al., 2015). In fact, the LTM deficit that we and others have observed in Mecp2 mutants, $24 \mathrm{~h}$ after training (Stearns et al., 2007; Tai et al., 2016), is reminiscent of similar deficits described in normal mice following pharmacologic blockade of activity in the PL after training and before testing for fear memory retrieval (Corcoran and Quirk, 2007). Interestingly, our data indicate that the PL to BLA projection circuitry involved in shortterm retrieval of conditioned fear memory is functional in Mecp2 mutants whereas the PL to dMT projection circuitry required for retrieval at $24 \mathrm{~h}$ is impaired. Given that mPFC activation during fear conditioning restores longterm retrieval to $\mathrm{Wt}$ levels, our data suggest that increasing the activity or excitability of MPFC pyramidal neurons during training enables the shift in dependence from PLBLA to PL-dMT projections that occurs by $24 \mathrm{~h}$ after training (Do-Monte et al., 2015).

The fact that both respiratory apneas and expression of cue-dependent conditioned fear memory can be restored to Wt levels in Mecp2 mutants indicates that the circuitry required for these behaviors is sufficiently intact to respond appropriately to activation of pyramidal neurons in the mPFC. This finding is consistent with the fact that loss of MeCP2 results in reversible changes in neural circuit function rather than neuronal cell loss or degeneration 
(Armstrong et al., 1995; Bauman et al., 1995; Guy et al., 2007; Robinson et al., 2012; Lang et al., 2013; Hao et al., 2015; Lu et al., 2016). Given that loss of Mecp2 results in functional hypoconnectivity in multiple cortical regions in addition to the mPFC (Katz et al., 2016), we predict that the approach described here is likely to be effective at ameliorating other symptoms in RTT mice as well. Moreover, these data raise the possibility that treatment strategies aimed at increasing activity in specific cortical networks may provide therapeutic benefit to RTT patients (see also Hao et al., 2015).

\section{References}

Abdala AP, Toward MA, Dutschmann M, Bissonnette JM, Paton JF (2016) Deficiency of GABAergic synaptic inhibition in the KöllikerFuse area underlies respiratory dysrhythmia in a mouse model of Rett syndrome. J Physiol 594:223-237. CrossRef

Adhikari A, Lerner TN, Finkelstein J, Pak S, Jennings JH, Davidson TJ, Ferenczi E, Gunaydin LA, Mirzabekov JJ, Ye L, Kim SY, Lei A, Deisseroth K (2015) Basomedial amygdala mediates top-down control of anxiety and fear. Nature 527:179-185. CrossRef Medline

Akbarian S (2003) The neurobiology of Rett syndrome. Neuroscientist 9:57-63. CrossRef

Alexander GM, Rogan SC, Abbas Al, Armbruster BN, Pei Y, Allen JA, Nonneman RJ, Hartmann J, Moy SS, Nicolelis MA, McNamara JO, Roth BL (2009) Remote control of neuronal activity in transgenic mice expressing evolved $G$ protein-coupled receptors. Neuron 63:27-39. CrossRef Medline

Alexandrov VG, Ivanova TG, Alexandrova NP (2007) Prefrontal control of respiration. J Physiol Pharmacol 58 [Suppl 5]:17-23.

Amir RE, Van den Veyver IB, Wan M, Tran CQ, Francke U, Zoghbi HY (1999) Rett syndrome is caused by mutations in X-linked MECP2, encoding methyl-CpG-binding protein 2. Nat Genet 23:185-188. CrossRef Medline

Armbruster BN, Li X, Pausch MH, Herlitze S, Roth BL (2007) Evolving the lock to fit the key to create a family of $G$ protein-coupled receptors potently activated by an inert ligand. Proc Natl Acad Sci USA 104:5163-5168. [CrossRef][CrossRef

Armstrong D, Dunn JK, Antalffy B, Trivedi R (1995) Selective dendritic alterations in the cortex of Rett syndrome. J Neuropathol Exp Neurol 54:195-201. Medline

Aschauer DF, Kreuz S, Rumpel S (2013) Analysis of transduction efficiency, tropism and axonal transport of AAV serotypes 1, 2, 5, 6, 8 and 9 in the mouse brain. PLoS One 8:e76310. CrossRef Medline

Atasoy D, Betley JN, Su HH, Sternson SM (2012) Deconstruction of a neural circuit for hunger. Nature 488:172-177. CrossRef Medline

Bauman ML, Kemper TL, Arin DM (1995) Microscopic observations of the brain in Rett syndrome. Neuropediatrics 26:105-108. CrossRef Medline

Belichenko NP, Belichenko PV, Mobley WC (2009) Evidence for both neuronal cell autonomous and nonautonomous effects of methylCpG-binding protein 2 in the cerebral cortex of female mice with Mecp2 mutation. Neurobiol Dis 34:71-77. CrossRef Medline

Chao HT, Zoghbi HY, Rosenmund C (2007) MeCP2 controls excitatory synaptic strength by regulating glutamatergic synapse number. Neuron 56:58-65. CrossRef Medline

Chen X, Choo H, Huang XP, Yang X, Stone O, Roth BL, Jin J (2015) The first structure-activity relationship studies for designer receptors exclusively activated by designer drugs. ACS Chem Neuroscie 6:476-484. CrossRef Medline

Corcoran KA, Quirk GJ (2007) Activity in prelimbic cortex is necessary for the expression of learned, but not innate, fears. J Neurosci 27:840-844. CrossRef Medline

Dhingra RR, Zhu Y, Jacono FJ, Katz DM, Galán RF, Dick TE (2013) Decreased Hering-Breuer input-output entrainment in a mouse model of Rett syndrome. Front Neural Circuits 7:42. CrossRef
Do-Monte FH, Quinones-Laracuente K, Quirk GJ (2015) A temporal shift in the circuits mediating retrieval of fear memory. Nature 519:460-463.

Durand S, Patrizi A, Quast KB, Hachigian L, Pavlyuk R, Saxena A, Carninci P, Hensch TK, Fagiolini M (2012) NMDA receptor regulation prevents regression of visual cortical function in the absence of Mecp2. Neuron 76:1078-1090. CrossRef Medline

Faul F, Erdfelder E, Lang AG, Buchner A (2007) G*Power 3: a flexible statistical power analysis program for the social, behavioral, and biomedical sciences. Behav Res Methods 39:175-191. Medline

Fassini A, Scopinho AA, Resstel LB, Corrêa FM (2016) NOP receptors in the prelimbic cortex have an inhibitory influence on cardiovascular responses induced by restraint stress. Neuropeptides 57:35-44. CrossRef Medline

Franklin KBJ, Paxinos G (2012) The mouse brain in stereotaxic coordinates. Ed 4. San Diego: Academic Press.

Frysztak RJ, Neafsey EJ (1991) The effect of medial frontal cortex lesions on respiration, "freezing," and ultrasonic vocalizations during conditioned emotional responses in rats. Cereb Cortex 1:418425. CrossRef

Ferguson SM, Eskenazi D, Ishikawa M, Wanat MJ, Phillips PEM, Dong Y, Roth BL, Neumaier JF (2011) Transient neuronal inhibition reveals opposing roles of indirect and direct pathways in sensitization. Nat Neurosci 14:22-24. CrossRef

Gabbott PL, Warner TA, Jays PR, Salway P, Busby SJ (2005) Prefrontal cortex in the rat: projections to subcortical autonomic, motor, and limbic centers. J Comp Neur 492:145-177. CrossRef Medline

Gomez JL, Bonaventura J, Lesniak W, Mathews WB, Sysa-Shah P, Rodriguez LA, Ellis RJ, Richie CT, Harvey BK, Dannals RF, Pomper MG, Bonci A, Michaelides M (2017) Chemogenetics revealed: DREADD occupancy and activation via converted clozapine. Science 357:503-507.

Guy J, Gan J, Selfridge J, Cobb S, Bird A (2007) Reversal of neurological defects in a mouse model of Rett syndrome. Science 315:1143-1147. CrossRef Medline

Hao S, Tang B, Wu Z, Ure K, Sun Y, Tao H, Gao Y, Patel AJ, Curry DJ, Samaco RC, Zoghbi HY, Tang J (2015) Forniceal deep brain stimulation rescues hippocampal memory in Rett syndrome mice. Nature 526:430-434. CrossRef Medline

Hassan SF, Cornish JL, Goodchild AK (2013) Respiratory, metabolic and cardiac functions are altered by disinhibition of subregions of the medial prefrontal cortex. J Physiol 591:6069-6088. CrossRef Medline

Katz DM, Dutschmann M, Ramirez JM, Hilaire G (2009) Breathing disorders in Rett syndrome: progressive neurochemical dysfunction in the respiratory network after birth. Respir Physiol Neurobiol 168:101-108. CrossRef

Katz DM, Bird A, Coenraads M, Gray SJ, Menon DU, Philpot BD, Tarquinio DC (2016) Rett syndrome: crossing the threshold to clinical translation. Trends Neurosci 39:100-113. CrossRef Medline

Kishi N, Macklis JD (2010) MeCP2 functions largely cell-autonomously, but also non-cell-autonomously, in neuronal maturation and dendritic arborization of cortical pyramidal neurons. Exp Neurol 222: 51-58. CrossRef Medline

Klose RJ, Sarraf SA, Schmiedeberg L, McDermott SM, Stancheva I, Bird AP (2005) DNA binding selectivity of MeCP2 due to a requirement for A/T sequences adjacent to methyl-CpG. Mol Cell 19:667678. CrossRef Medline

Kong D, Tong Q, Ye C, Koda S, Fuller PM, Krashes MJ, Vong L, Ray RS, Olson DP, Lowell BB (2012) GABAergic RIP-Cre neurons in the arcuate nucleus selectively regulate energy expenditure. Cell 151: 645-657. CrossRef Medline

Krashes MJ, Koda S, Ye C, Rogan SC, Adams AC, Cusher DS, Maratos-Flier E, Roth BL, Lowell BB (2011) Rapid, reversible activation of AgRP neurons drives feeding behavior in mice. J Clin Invest 121:1424-1428. CrossRef

Kron M, Howell CJ, Adams IT, Ransbottom M, Christian D, Ogier M, Katz DM (2012) Brain activity mapping in Mecp2 mutant mice 
reveals functional deficits in forebrain circuits, including key nodes in the default mode network, that are reversed with ketamine treatment. J Neurosci 32:13860-13872. CrossRef Medline

Lang M, Wither RG, Brotchie JM, Wu C, Zhang L, Eubanks JH (2013) Selective preservation of MeCP2 in catecholaminergic cells is sufficient to improve the behavioral phenotype of male and female Mecp2-deficient mice. Hum Mol Genet 22:358-371. CrossRef Medline

Loffler S, Korber J, Nubbemeyer U, Fehsel K (2012) Comment on "Impaired respiratory and body temperature control upon acute serotonergic neuron inhibition." Science 337:646 CrossRef

Lu H, Ash RT, He L, Kee SE, Wang W, Yu D, Hao S, Meng X, Ure K, Ito-Ishida A, Tang B, Sun Y, Ji D, Tang J, Arenkiel BR, Smirnakis SM, Zoghbi HY (2016) Loss and gain of MeCP2 cause similar hippocampal circuit dysfunction that is rescued by deep brain stimulation in a Rett syndrome mouse model. Neuron 91:739-747. CrossRef

Neafsey EJ (1990) Prefrontal cortical control of the autonomic nervous system: anatomical and physiological observations. Prog Brain Res 85:147-165; discussion 165-166.

Pratt JA, Winchester C, Egerton A, Cochran SM, Morris BJ (2008) Modelling prefrontal cortex deficits in schizophrenia: implications for treatment. Br J Pharmacol 153 [Suppl 1]:S465-S470. CrossRef Medline

Ramirez JM, Ward CS, Neul JL (2013) Breathing challenges in Rett syndrome: lessons learned from humans and animal models. Respir Physiol Neurobiol 189:280-287. CrossRef Medline

Ren J, Ding X, Funk GD, Greer JJ (2012) Anxiety-related mechanisms of respiratory dysfunction in a mouse model of Rett syndrome. J Neurosci 32:17230-17240. CrossRef Medline

Riga D, Matos MR, Glas A, Smit AB, Spijker S, Van den Oever MC (2014) Optogenetic dissection of medial prefrontal cortex circuitry. Front Syst Neurosci 8:230. CrossRef Medline

Robinson L, Guy J, McKay L, Brockett E, Spike RC, Selfridge J, De Sousa D, Merusi C, Riedel G, Bird A, Cobb SR (2012) Morphological and functional reversal of phenotypes in a mouse model of Rett syndrome. Brain 135:2699-2710. CrossRef Medline

Sceniak MP, Lang M, Enomoto AC, James Howell C, Hermes DJ, Katz DM (2015) Mechanisms of functional hypoconnectivity in the medial prefrontal cortex of Mecp2 null mice. Cereb Cortex 26:1938-1956.

Schafe GE, LeDoux JE (2000) Memory consolidation of auditory pavlovian fear conditioning requires protein synthesis and protein kinase $A$ in the amygdala. J Neurosci 20:RC96. Medline

Scofield MD, Boger HA, Smith RJ, Li H, Haydon PG, Kalivas PW (2015) Gq-DREADD selectively initiates glial glutamate release and inhibits cue-induced cocaine seeking. Biol Psychiatry 78:441-451. CrossRef Medline

Scopinho AA, Tavares RF, Corrêa FM (2009) The medial forebrain bundle mediates cardiovascular responses to electrical stimulation of the medial prefrontal cortex. Auton Neurosci 147:38-47. CrossRef Medline

Shepherd GM (2013) Corticostriatal connectivity and its role in disease. Nat Rev Neurosci 14:278-291. CrossRef
Shepherd GM, Katz DM (2011) Synaptic microcircuit dysfunction in genetic models of neurodevelopmental disorders: focus on Mecp2 and Met. Curr Opin Neurobiol 21:827-833. CrossRef Medline

Sierra-Mercado D Jr, Corcoran KA, Lebrón-Milad K, Quirk GJ (2006) Inactivation of the ventromedial prefrontal cortex reduces expression of conditioned fear and impairs subsequent recall of extinction. Eur J Neurosci 24:1751-1758. CrossRef

Sierra-Mercado D, Padilla-Coreano N, Quirk GJ (2011) Dissociable roles of prelimbic and infralimbic cortices, ventral hippocampus, and basolateral amygdala in the expression and extinction of conditioned fear. Neuropsychopharmacology 36:529-538. CrossRef Medline

Stachniak TJ, Ghosh A, Sternson SM (2014) Chemogenetic synaptic silencing of neural circuits localizes a hypothalamus-midbrain pathway for feeding behavior. Neuron 82:797-808. CrossRef Medline

Stearns NA, Schaevitz LR, Bowling H, Nag N, Berger UV, BergerSweeney J (2007) Behavioral and anatomical abnormalities in Mecp2 mutant mice: a model for Rett syndrome. Neuroscience 146:907921. CrossRef Medline

Stettner GM, Huppke P, Brendel C, Richter DW, Gärtner J, Dutschmann M (2007) Breathing dysfunctions associated with impaired control of postinspiratory activity in Mecp2-/y knockout mice. J Physiol 579:863-876. CrossRef

Stuss DP, Boyd JD, Levin DB, Delaney KR (2012) MeCP2 mutation results in compartment-specific reductions in dendritic branching and spine density in layer 5 motor cortical neurons of YFP-H mice. PLoS One 7:e31896. CrossRef Medline

Tai DJ, Liu YC, Hsu WL, Ma YL, Cheng SJ, Liu SY, Lee EH (2016) MeCP2 SUMOylation rescues Mecp2-mutant-induced behavioural deficits in a mouse model of Rett syndrome. Nat Commun 7:10552. CrossRef

Urban DJ, Roth BL (2015) DREADDs (designer receptors exclusively activated by designer drugs): chemogenetic tools with therapeutic utility. Annu Rev Pharmacol Toxicol 55:399-417. CrossRef

Vardy E, Robinson JE, Li C, Olsen RHJ, DiBerto JF, Giguere PM, Sassano FM, Huang XP, Zhu H, Urban DJ, White KL, Rittiner JE, Crowley NA, Pleil KE, Mazzone CM, Mosier PD, Song J, Kash TL, Malanga CJ, Krashes MJ, et al. (2015) A new DREADD facilitates the multiplexed chemogenetic interrogation of behavior. Neuron 86:936-946. CrossRef Medline

Vertes RP (2004) Differential projections of the infralimbic and prelimbic cortex in the rat. Synapse 51:32-58. CrossRef Medline

Weese-Mayer DE, Lieske SP, Boothby CM, Kenny AS, Bennett HL, Ramirez JM (2008) Autonomic dysregulation in young girls with Rett syndrome during nighttime in-home recordings. Pediatr Pulmonol 43:1045-1060. CrossRef Medline

Whissell PD, Tohyama S, Martin LJ (2016) The use of DREADDs to deconstruct behavior. Front Genet 7:70. CrossRef Medline

Woodyatt GC, Murdoch BE (1996) The effect of the presentation of visual and auditory stimuli on the breathing patterns of two girls with Rett syndrome. J Intellect Disabil Res 40:252-259. CrossRef 